\title{
APURDUTI
}

Euskal ikerketen aldizkaria | Revue d'études basques |

Revista de estudios vascos | Basque studies review

$9 \mid 2004$

Numéro IX

\section{J. Garat-en Lettre sur Bayonne et sur les Basques « Mercure de France » aldizkarian (1783-02-08)}

Jean Casenave

\section{OpenEdition \\ Journals}

Édition électronique

URL : http://journals.openedition.org/lapurdum/814

DOI : 10.4000/lapurdum.814

ISSN : 1965-0655

Éditeur

IKER

Édition imprimée

Date de publication : 1 novembre 2004

Pagination : $97-116$

ISBN : 2-68781-376-X

ISSN : $1273-3830$

Référence électronique

Jean Casenave, «D. J. Garat-en Lettre sur Bayonne et sur les Basques « Mercure de France » aldizkarian (1783-02-08) », Lapurdum [En ligne], 9 | 2004, mis en ligne le 01 mars 2009, consulté le 19 avril 2019. URL : http://journals.openedition.org/lapurdum/814 ; DOI : 10.4000/lapurdum.814 


\section{D.J. Garat-en Lettre sur Bayonne et sur les Basques}

« Mercure de France » aldizkarian (1783-02-08)

Ilustrazioak edo Argiek Euskal Herrian ukan duten eragina ongi aztertua izan da Hegoaldeko eskualdearentzat bainan aise guttiago iparraldekoarentzat. Orain arte, eztabaida politiko eta juridikoen inguruan, garai hartan, agertu ziren idazlanak aipatuak izan dira batez ere : hala nola Sanadon-ek, Bela Zaldunaren esku-izkribuen gainean oinarriturik Iraultza aintzin idatzi zuen L'Essai sur la noblesse des Basques. Eugène eta Manex Goyhenetche historialariek, azken urte hauetan oraindik, Sanadon-ekin batean, Polverel-en idazlanen ekarpena ikertua dute. Tx. Peillen-ek eta Manex Goyhenetchek, Egiategi-ren idazlanak aipatu dituzte ere. Lan horietan, XVIII-garren mendeko ideiak altxatzen dituzte baita ere garaiko hiztegian "Filosofoak» deitua zen taldearen eragina nabari dela diote, bainan saiheska bezala. Horrek erran nahi ote du Europa guzian hedatzen ari ziren ideia berriek ez dutela eragin zuzenik ukan Euskal Herriari buruz egin izan diren lanetan ? Egia da, mementoan dokumentoak falta zaizkigula horren aztertzeko. Halarik ere, gauza jakina da, hemendik jalgi zenbait gizonek parte hartu zutela Iraultza aintzineko eztabaida nagusietan. Denei Garat anaien ibilbidea heldu zaigu gogora, batez ere Iraultza denboran ukan zuten garrantziarengatik. Bizkitartean, guttiago aipatzen da jende horiek ordu arte egin zutena.

Alta, Iraultzaren eragileak izan baino lehen, XVIII-garren mendeko jendeak izan dira bete betean, hots « Argien » garaikideak eta lekukoak. Orroit gaitezen Dominique, haurrideetarik lehena 1735-an sortua zela ; beraz, 54 urte bazituen Iraultza abiatu orduko eta Bordaleko plazan abokatu eta ideia berrien hedatzaile bezala ezagutua zen. Dominique Joseph, haren anaia famatuena, 1749-an sortua, 40 urte bazituen 1789-an eta hamaika urte iragan zituen Parisen, idazle eta entziklopedista ezagutuenen artean. Beraz, dudarik gabe beren bizi publikoaren parte handi bat ereman zuten Frantziako Argien garai dirdiratsuenean.

Dominique-Joseph orduko « Letren Errepublika »-ren erdian bizi izan da Parisera heldu bezain laster, hots 1778-tik aintzina. Segurki, adinarengatik Entziklopedisten lehen belaunaldiarekin ez zuen harreman hesturik ukan bainan bigarren eta hirugarrenarekin bai, hala nola Morellet, Condorcet edo Suard-rekin. Beraz, ontsalaz, haren idazlanetan Argien eragin zuzena aurki daiteke. Eta hala da dudarik gabe ; Mercure de France orduko astekari famatuan argitaratu zituen artikuluetan, behin baino gehiagotan Filosofoen izenak, idazlanak eta ideiak aipatzen eta hedatzen ditu. 1783-an publikatu zuen Lettre sur Bayonne et sur les Basques deitzen den idazlanean ideia berrien eragina atxematen da Euskal Herriari buruz egina den gogoeta batean. Entziklopedia garaiak eskaini duen lekukotasun aberatsena bezala har daiteke testu hori, hortan filosofoen eragina ezagun baita hastetik buru.

Idazki horrekin ez da hastapenean aipatuak (Sanadon, Polverel) izan diren ikuspegien ildotik ibiltzen; izen eta erreferentzia berriak erabiltzen ditu nasaiki idazlan literario eta filosofiko baten plazaratzeko gogoarekin. Ahalaz, orduz geroz guttietsia izan den ekarpen hori nahi genuke argitara eman, batez ere Argien mirailan eskaintzen duen Euskaldunaren potretarengatik. Horrengatik, sartze gisa ematen dugun aurkezpen honen ondotik, jatorrizko testua emanen dugu. 


\section{Idazlanaren aurkezpena :}

\subsection{Argitalpena :}

La Lettre sur Bayonne et les Basques Mercure de France astekarian argitaratua izan da otsailaren 8-an. Garaiko ohiduren arabera, zabaltzeko ziren berrien artean agerkari bakoitzak eremu bat erosten zuen. Panckouke argitaratzaileak, 1778-an erosia du Mercure de France astekaria eta harekin batean, «Belles Lettres » saileko berrien hedatzeko premia. Orroitarazi behar da Panckoucke-n argitaletxeak, Diderot et d'Alembert idazleek kudeatu zuten Entziklopedia famatuaren berrargitaratze eskubideak erosi zituela lehen argitalpena bukatu baino lehen, 1768-an hain zuzen ${ }^{1}$ eta Encyclopédie Méthodique delakoaren proiektoa ereman zuela aintzina Iraultza garaia arte. Preseski, Entziklopediaren berridazketa horren burutzeko, Garat bezalako filosofo eta idazle talde zabal bat muntatu zuen. Karia hortara, gazte horiek Entziklopedisten belaunaldi historikoaren partaide gehienak -Diderot, Rousseau, D'Alembert, Helvetius- ezagutu zituzten eta bigarren belaunaldikoekin lanean arizan ziren, hala nola Morellet, Suard, Condorcet, etb.

Beraz, 1778-tik goiti, Garat-ek artikuluak argitaratzen ditu Mercure de France agerkarian. Astekari horren irakurlegoaren parte handiena Frantzian aurkitzen zen dudarik gabe, batez ere hiri handietan, bainan Europa mailan zabaltzen zen ere, familia eta izen handien artera. Daniel Roche XVIII-garren mendeko mugimendu akademikoaren adituaren arabera ${ }^{2}$, "Le Mercure, c'est la presse des châteaux, des intendants et des parlementaires » (Mercure, jauregietako kazetagintza zen, administrari eta biltzar handietako ordezkariena.). Altxatzekoa da halarik ere hartzaile bat edo beste bazela Euskal Herrian.

Ikusiz zein zen astekariaren kokagunea orduko kulturaren eremuan, nabari da ideia berriei guziz idekia zen irakurlego jakintsun batentzat ari zela Garat bere idazlanetan. Bestaldetik, Michel Duhart-ek ${ }^{3}$, erakusten digunez, garaiko «Salon» edo biltoki aintzinatuetan ibiltzen zen, besteak beste Suard jaun-andere ospetsuek antolatzen eta kudeatzen zutena. Orduan, eguneroko gizarte harremanetan erabiltzen zituen solasaldiengatik, filosofoen taldeko partaide bezala - bigarren edo hirugarren mailakoa izanik ere- ikusi behar da hogeitabat orrialdeko idazki trinko hortan gostukoak eta ohizkoak zituen erreferentzia eta solasgaiak erabiltzen zituela. Hots, Argien mirailan idazten du Euskal Herriari buruzko artikulu hori, bere berea senditzen duen sor herria kanpoko jende argituei aurkezteko gogoarekin.

\subsection{Idazlanaren gaia eta egitura :}

Artikulu hortan, Bordaleko Akademian izan den biltzar baten berri emaiten du. Biltzarraren egun hartan, Dupré de Saint-Maur, Guyenne ${ }^{4}$ eskualdeko buruzagiak, Baionako hiria eta Lapurdi probintziaren geroari buruz argitaratu zuen txostena ${ }^{5}$ aipatu zuen bere solaskideen aintzinean. Ondotik, egun berean eta biltzar berean emanak izan ziren beste bi mintzaldi aipatzen ditu Garat-ek, lehena Quintilien Erroma zaharreko garaian izan zen hizlari famatuari buruz eta bigarrena Akitaniako Alienor-i buruz. Bi parte nagusi horien bilduma

\footnotetext{
${ }^{1}$ Ikus : Robert Darnton L'Aventure de l'Encyclopédie, 1979 - 1982 Frantses itzulpenarentzat.

${ }^{2}$ Daniel Roche, Le Siècle des Lumières en Province, Paris, 1978.

${ }^{3}$ Michel Duhart, Dominique-Joseph Garat (1749-1823), Bulletin de la Société des Sciences, Lettres et Arts de Bayonne, 1992-1993.

${ }_{5}^{4}$ Guyenne : Erregimen zaharreko eremu zati bat, gutti gora behera, oraiko Akitania.

5 Mémoire sur la Décadence du Commerce de Bayonne et de Saint-Jean-de-Luz, 1782.
} 
nasaien artean, Eskualdunei buruz, bere baitarik, aurkezpen luze eta trinkoa egiten du, Herri edo jendalde berezi eta ohargarri gisa aurkezten dituelarik.

Lehen partean, Administalariaren ideiak eta arrazoinkatzeko bidea bere kondu berritz hartzen ditu. Zenbait urte geroago izan beharra zen Lapurdiko ordezkariaren mintza moldea erabiltzen du zati hortan Garatek, hots abokatuaren doinua. Bigarrenean, "Argien" garaiko filosofoarena erabiltzen du Euskal Herria aurkezteko xedearekin, eta hirugarrenean, historia egilearen egitekoa aipatzen du, bi hizlarien lanari buruz oharrak eginez. Hiru parteak lotzen ditu elgarri Euskal Herria gai nagusi edo orokor bezala hartuz.

\subsection{Euskaldunaren potreta berritua :}

Garat baino lehen, hainbat aipaldi eta potreta egin zen Euskaldunen aurkezteko, Zahar Arotik XVIII-garren mendea arte. Aintzinekoei begira, Euskaldunen itxura aldatzen duela erran daiteke nahiz zenbait pundutan ildo beretik heldu den, hala nola nortasunaren gaian. Harek ere Euskaldunen berezitasuna azpimarratuz hasten du bere aurkezpena :

«Dans ce pays, l'un des trois cantons qui forment la Biscaye Française,vit un Peuple qui, attaché à la France par l'amour que des sujets doivent à leur Souverain, diffère d'ailleurs absolument des Français par son origine, sa langue, ses coutumes, ses mœurs et son caractère. »

Hortarik abiatuz, Euskaldunen ekarpenak, bi mailetan ikusten eta sailkatzen ditu : alde batetik lekuko gisa aurkezten ditu eta bestaldetik eredu gisa. Berezitasunen lerroan, aspaldikotasuna aintzinatua izan da Zahar Arotik hara. Beraz, Garat-en ustez, aspaldikoak izanik Euskaldunek lehengo aroen lekukotasuna ekartzen dute berekin :

«... en observant le Basque dans ce petit nombre même de rapports que peut lui donner un état de société simple, on peut voir comment les Anciens d'y prenaient pour établir la vertu et le bonheur de l'homme social sur les sentimens et les besoins les plus naturels à l'homme. »

Lekuko paregabeak dira Euskaldunak, gizarte antolaketa mailan, Naturaren arabera bizi baitira, multzoan edo jendalde nasaian egonik ere. Bainan, lekuko dira ere euskarari esker Garat-en ustez, lehen aroetako hizkuntzen alde onak begiratu baititu euskal mintzairak mendeetan zehar :

" Son origine touche à celle des Peuples qui commencent l'Histoire... »

Eta mugatua izanik ere Euskaldunen bilakaera historikoarengatik, den bezala denboran zituen aberastasunak atxiki ditu :

«Elle est bornée, il est vrai dans les objets que peut connaître un Peuple qui n'est qu'agriculteur; mais quelle féconde richesse d'idées et de sentimens elle a pu faire naître dans le petit nombre d'objets où elle se renferme ! »

Bainan, Garat-ek ez ditu Euskaldunak baitezpada iraganean gakatzen, lekukotasunarekin batean, eredu bat ekartzen baitute batez ere gizarte antolaketa mailan :

"Chez ce Peuple étranger à tous les Arts et à toutes les Sciences, le sentiment des droits de l'homme est si profond et si développé, qu'il sait en tirer la connaissance de tous ses devoirs et de tous ses droits dans la société ».

Voltaire ideien kontra joanez (gizonak egiten dituen aintzinamenduen aurreratze ezin gelditua), "Lehen jendaldeen » antolaketa soziala eredugarria daitekeela " Argien garaiko » lege eta gizarte erreformatzaileentzat pentsatzen du Garat-k, batez ere libertatea eta jendeen arteko berdintasuna (Erregimen zaharrak finkatu zuen ordreen araberako antolaketaren kontra doana) baitituzte jarri ardatz nagusi gisa, Euskaldunen artean bezala :

«Le Laboureur, fier de ce titre qu'on lui donne et qu'il prend dans toutes les occasions comme un titre d'honneur, s'assiet à la table du Gentilhomme, et s'y croit à sa place, et le Gentilhomme pense comme lui . » 
Azkenean, Garat-ek aintzinatzen du «eredu edo molde zaharreko » jendalde horrek baduela etorkizun ederra :

«Il est facile de voir quel parti un Gouvernement éclairé peut tirer d'un Peuple chez lequel cette opinion, qui a fait la grandeur des Nations anciennes, a toute la force que les siècles donnent aux opinions. »

\section{Idazlanaren testu-ingurua :}

Euskal Herria ez zen asko aipatua orduko frantses agerkarietan. Halarik ere, kasu berezi batzu izan ziren, hala nola Mémoires de Trévoux Jesuisten aldizkarian baita ere D'Alembert eta Diderot-en Entziklopedian.

2.1. Euskal Herriaren irudia orduko frantses argitalpenetan :

Mémoires de Trévoux agerkarian artikulu luze eta guziz baikorra ${ }^{6}$ agertu zen Larramendiren hiztegiaren aipatzeko, 1748-an.

Bestalde, Euskaldunen ezagutzeko beste iturri nagusia Entziklopedia izan da dudarik gabe orduko jende ikasientzat. Hainbat sartze aurki zaitekeen Euskal Herriari buruz. Ondoko artikuluak badira obraren baitako sailkatze moduaren arabera emanak :

- Géographie : Alava, Biscaye, Guipuscoa, Labourd, Navarre (La Basse, La Haute), Soule ; Bilbao, Bayonne, Vitoria, etb.

- Histoire: Basques, Biscayens, Gascogne, Navarre, Vascones, etb.

- Langue : Langue des Cantabres («Gure aitaren » hastapena ekarria da adibide gisa, Leizarragaren liburutik hartua, erran nahi baita, Jaunari hika ari zaion bertsioan), etb.

Artikulu gehienak, D.J. siñatuak dira, hots Jaucourt, Diderot-en lankideak eginak. Bigarren eskuko xehetasunak ematen dira, iturri zaharkituak gehienetan eta kontradizio zenbaitekin nahasteka, batez ere hizkuntzaren gainean. Beraz, erran daiteke, guti dokumentatua zen gai bat erabiltzen duela Garat-ek bere gutunean.

\subsection{Argien hiztegia Dominique-Joseph Garat-en idazlanean :}

Euskal Herriaren aipatzeko, hurbiletik ezagutzen zituen konzeptoak erabiltzen ditu Garatek, Frantziako « Argien » aldeko filosofoek landu eta plazaratu zituztenak hain zuzen. Eragin horren lekukotasuna hiztegian berean aurki daiteke, orduko hitz gako nagusiak behin eta berritz heldu baitira, ondoko aipamenetan agertzen den bezala :

Bonheur (Zoriona) : «Le Gouvernement qui seul possède les moyens de rendre à ces vastes Pays leur Bonheur et leurs Peuples, doit parfaitement être secondé par l'activité naturelle, le caractère et le génie de leurs habitants. »

Intérêt général (Ororen aldeko jokaera) : "L’intérêt général du Royaume est attaché aussi au Port de Bayonne et aux Pays qui l'environnent. »

Vertu (Onerateko joera): "Le Basque a de la bonté plutôt que des vertus. ».

Bonté naturelle (jitezko edo jatorrizko Ongintza) : «Le Basque est bon mais de cette bonté naturelle qui ne préserve pas des fureurs des passions. »

Nature, organisation sociale (Natura, Gizarte antolaketa): «Les lois éternelles de la Nature servent de garants aux lois sociales $»$.

Homme, droits, devoirs, société (Gizakia, eskubideak, eginbideak, gizartea) : "Chez ce peuple étranger à tous les Arts et à toutes les Sciences, le sentiment des droits de l'homme est si profond et si développé qu'il sait en tirer la connaissance de tous ses devoirs et de tous ses droits dans la société. »

\footnotetext{
${ }^{6}$ Larramendi en las Mémoires de Trévoux, J.I. Tellechea Idigoras, Symbolae Luduvico Mitxelena septuagenario oblatae, Vitoria, 1985.
} 
Raison, énergie, sentiments (Arrazoinamendua, kemena, sendimenak) : «Au reste, je suis persuadé que tout ce qu'il y a raison et d'étendue dans les idées de ce peuple, d'énergique, de fin dans ses sentimens, il le doit beaucoup à la langue qu'il parle. »

Euskaldunaren potreta « Argien » ispiluan egina dela hitzetarik agerian gelditzen da. Ideia horien bitartez gaia errotik berritzen zuen Garat-k eta erran daiteke alde hortarik adibide eta saio bakarra bezala gelditzen dela idazlan hori. Bainan guziz eraikia, egituratua eta trinkoa denez geroz, azterketa zehatza merezi du eta bestalde eginen dugu, gaurko aurkezpen orokorretik berex egitekoa baita.

\subsection{Testu-artekotasuna :}

Garat-en artikulua ez da bakarrik garai baten lekukotasuna. Idazlan aberatsa da beste idazlan askorekin harremanetan eta solasean bezala baita. Testu-artekotasuna nabaria da orrialde horietan, batzutan argiki, erreferentziak agerian uzten dituelako, bestetan molde isil batez. Berak ${ }^{7}$ idatzi du behin baino gehiagotan irakurle handia eta jarraikia izan dela Bordalen ikasle zenean eta Parisen, Mercure de France agerkarian eta Panckouke argitaletxean liburu kritikari eta idazle gisa lanean ari zelarik. Ikasketen denboran Zahar aroko klasikoak landu ditu baita ere, frantses literaturaren maisuak, batez ere XVII-garren mendekoak. Bainan, Bordaleko ikastexeetan, filosofoak ere irakurri ditu eta besteak beste Locke eta Bacon pentsalari anglesak. Idazle garaikideak ere gostukoak zituen denbora haietan eta haietarik zenbait miresten zituen, hala nola Rousseau, Parisera heldu eta, bisitatuko duena Rue Plâtrière berak kondatua duen bezala. Gazte denboran irakurri zituen beste frango ere elekatu ditu Pariseko "salon" edo bilgune famatuenetan : Diderot, Marmontel, Raynal, Morellet, etb.

Beraz, ez da harritzeko, garaiko obra eta idazle nagusi batzuekin "solasaldia" segitzen baldin badu bere gutunean. Testuan zehar, esplizituki ematen dituen erreferentziak ondoko hauek dira :

- Autore klasikoak :

Zahar arokoak $:$ Aristote, Longin, Platon, Pline l'Ancien, Pline le Jeune, Quintilien, Sénèque, Suétone, Tacite.

Modernoak :Montaigne.

- "Argien" garaiko idazleak :

Burlamaque, Hume, Montesquieu, Voltaire,

- « Argien » garaiko idazlanak :

Principes du droit naturel, Genève 1747 (Burlamaqui Jean-Jacques : Burlamaque deitzen du Garat-ek, garai hartan jende eta toki izen arrotzak frantsesten baitziren).

Bainan, esplizituki bezainbat, molde isilean ekarrarazten ditu testura bere irakurketak, erran nahi duenaren indartzeko eta hori iturririk aipatu gabe, jende ikasien arteko solasaldian garai hartan egin zaitekeen bezala, Mercure astekariaren idazle eta irakurleek gutti gora behera liburu berdinak irakurtzen baitzituzten.

Hala nola, erraiten duelarik, « Si des Voyageurs, qui savent observer et peindre des Peuples, ne nous avaient pas fait connaître les hommes qu'ils ont vus dans les vallées et les montagnes de la Suisse », pentsa daiteke Rousseau duela gogoan, Saussure edo Gesnner ez bada. Bainan, ikusiz geroz Euskal emaztearen aipatzeko erabiltzen duela erreferentzia hori, Suizako emazteekin konparaketa baten osatzeko gisa, erran daiteke, hain segur, "La lettre sur le Valais » deitzen den lehen parteko XIII-garren kapitulua duela aipagai, La Nouvelle Hélö̈se ( 1761) eleberrian aurkitzen dena.

« Notre inquiète curiosité va chercher aux deux Pôles des peuplades de Sauvages pour y observer l'homme dans la simplicité des besoins et des mœurs de la Nature, et nous ne

\footnotetext{
${ }^{7}$ Michel Duhart-ek xehetasun guziak ematen ditu idatzi duen Garat-en biografian irakurketa horiei buruz.
} 
daignons pas jeter un regard sur un Peuple qui est à côté de nous, presque sous nos yeux, et qui nous offre l'homme tel qu'il était sous l'influence des institutions primitives, où l'instinct de la Nature était l'unique législateur des Sociétés.» Dudarik gabe, solas horiek harremanetan daude XVIII-garren mende guzian argitaratuak izan diren bidai liburuekin, Lahontan-en Dialogues de M. le baron de La Hontan et d'un sauvage dans l'Amérique (1703), Raynal abadearen Histoire des deux Indes (1770) arrakasta handiko liburuarekin, edo oraindik, Cook, Bougainville edo La Pérouse itsas gizonen aurkikuntza lekukotasunekin ; eta hori, gai berari buruz eginak izan ziren eleberri eta fikzioak aipatu gabe. Bainan, ikusiz zer doinu ezezkorra erabiltzen duen, pentsa daiteke, Diderot-en Supplément au voyage de Bougainville (1773) idazlan kritikoaren bideari jarraikitzen zaiola.

Euskara eta hizkuntzaren gaia hunkitzen duelarik, berdin, ongi ezagutzen eta hurbiletik irakurri zituen Court de Gébelin ( Le Monde primitif, 1773) eta Condillac dituela eredu gisa. Halaber, laboraria eta haren bizi moldea goraipatzen dituelarik, Entziklopedian aurkitzen diren artikulu nagusi batzu erabiltzen ditu, batez ere, «Bonheur», «Laboureur », «Peuple», deitzen direnak, ideia berdintsuak hedatzen baititu euskal nekazaria aipaterakoan.

Garat irakurle bikaina izan da eta hortarik heldu da haren «gutunaren » aberastasuna eta Euskaldunaren potret trinkoaren garrantzia. Alde batetik, Sanadon eta Polverel-ek ez bezala, literatura eta filosofia garaikideen baitan (bainan «Argien » garaian biek bat egiten zuten hein handi batean) oinarritzen ditu bere oharrak, eta bestaldetik, guziz nabari da ez dituela bigarren eskuko erreferentziak erabiltzen, orduko euskal literaturan artetan gertatzen den bezala.

\section{Idazlanaren ekarpena :}

Dudarik gabe, Garat-ek gaia berritzen du bere gutunean eta idazlanaren ekarpena neurtu nahi bada, bi alde nagusi berexi behar dira : alde batetik, gaia ikusgai bilaka arazten du Frantzia mailan eta Europako Letren Errepublikaren baitan; bestaldetik, gaiari buruzko erreferentiak eta haren lantzeko sentsibilitatea berritzen eta aberasten ditu.

3.1. Euskaldunak eta Euskal Herria :

3.1.1. Gaia osatu eta finkatu :

Gaia argi handira ekartzen du Mercure de France bezalako agerkari batean toki bat egiten diolarik eta, jakintsunen eta adituen ingurutik hara erakartzen du goi maileko irakurlego zabalago baten menera. Ospea biltzeaz gain, funtsezko informazio lana egiten du, Entziklopediak emana osatzen baitu, neurri handi batean, lehen aldikotz irakurlego hoin zabal batentzat, Euskal Herriaren berezitasunak lantzen eta erakusten baititu eta hori guzia lekukotasun segurren gainean oinarrituz -berea eta ezagutzen dituen adituena. Gutun hortan ez ditu Entziklopedian bezala bigarren eskuko jakitateak erabiltzen hizkuntzaren aipatzeko edo gizarte antolaketaren berezitasunen azaltzeko.

\subsubsection{Gaia berritu :}

Hein handi batean ere, gaia berritzen du eta hori alde ezberdin batzuetarik. Konzeptoen aldetik lehenik edo hobe erranez konzepto mota nahastekatzeagatik. Hain zuzen, idazlan berean eta, hori, lehen partean bereziki bainan besteetan ere, arazo ekonomikoak (modernitatea) eta eskualdearen garapena aipatzen ditu alde kulturalarekin batean (tradizioa, ondarea), Entziklopedistek ohi zuten bezala.

Beste berritasun bat ere nabari da Euskal gaien lantzeko moldean. Garaiko idazle gehienek ez bezala ez du ordu arte erabiltzen zen mitologia batere baliatzen Euskaldunen berezitasunak azpimarratzeko ; Kantabreak, Japhet, hots, Euskaldunen aspaldikotasuna agerian uzteko erakartzen ziren argumentoak alde batera utzirik, XVIII-garren mendean 
agertu ziren hizkuntzen teoriak eta lehengo jendaldeen aurkezteko erabiliak ziren ideiak hartzen ditu bere gain, Euskaldunen kasuari egokitzeko gisan. Condillac-en ikasle eta jarraikitzailea izanki, haren arrazoinen bidetik ibiltzen da hizkuntzaren problematikan eta Buffon, Court de Gébelin eta Diderot-enak erabiltzen ditu "salbaien" gaian. Beraz, parekatze lan hortan, konparagai berriak sar arazten ditu, Diderot-en Tahiti eta eskualde urruneko salbaiak edo Rousseau-ren Suiza, besteak beste. Alde hortarik ere, aberaste handia da. Gaiaren ordu arteko mugak zabaltzen baldin baditu ditu geografia mailan, filosofiaren aldetik ere uste baino haratago erematen ditu, lehen gizarteak eta giza eskubideen ikus moldeak lantzen dituelarik batez ere .

\subsection{Sentsibilitate berria :}

Ideia berriez gain, beste aldaketa da nabaritzen da Garat-en ikuspegian. Iraultza aintzin literatura eta arteen bitartez Europa guzian hedatzen ari den sentsibilitate berria sar arazten du lehen aldirako Euskal gaietan.

3.2.1. Eskualdeetako jendaldeak eta herri kultura :

Literatura mailan, Richardson, Rousseau eta Goethe-en idazlanetan aurkitzen da izpiritu hori eta adibide gisa, eman daiteke jadanik aipatua dugun La Nouvelle Héloïse eleberria. Garat-ek ere, idatz-molde guziz baikor bat erabiltzen du Baserriko biziaren erakustekoeta Euskal laborarien ohidurak eta lanak aipatzeko unean. Bainan, nekazarien alderako joera literario berri hori ez zen pastoralen (artzain eleberriak) moduko eleberri batzuen osagai bat bakarrik. Mugimendua hedatuago eta konplexuagoa izan zen, Nicolas Restif de la Bretonne-n La vie de mon père (1779) arrakastak frogatu zuen bezala. Mende klasikotik hara (XVIIgarrena) gizarte maileko ezagupen eskasez «ikusten » ez ziren edo gaitzietsiak izan ziren jende xeheak eta herri kulturak literatur gai bilakatu ziren XVIII-garren mende ondarretik aintzina, XIX-garren mende guzian. Eskualdeetan bizi diren jendaldeak fikzio gai ohoragarriak izan dira zenbait urte berantago G. Sand-entzat. Jende xehe horien ohidurak, kantuak eta sorkuntza lanak bilduak izan ziren eta imitazioak izan zituzten Erromantikoen garaian, hala nola Keltiarren inguruan obratu ziren ikerketak eta liburugintza nasaia.

\subsubsection{Aurre-Erromantikoen gaiak :}

Sentsibilitate berriak, frantses iraultzaren ondotik, aurre-erromantiko deituak diren gaiak erakarri ditu, harri eta harresi zahar erorien modarekin batean, Germaine de Staël ${ }^{8}$, Volney $^{9}$ eta, geroxago Chateaubriand ${ }^{10}$-en obretara. Iraganaren nostalgia eta galtzearen arrangura ageri dira jadanik Garat-en gutunean Euskal jendaldearen desagertzeari buruz ari delarik pentsaketa :

"Celle des Basques diminue sensiblement tous le jours pour des causes dont il n'est pas possible d'arrêter l'influence ; (...) elle se perd, le pays se dépeuple et si l'on ne se hâte d'y porter des secours, ce qu'il en restera ne servira plus qu'à faire voir quelle race d'hommes on a perdue. »

\section{Idazlanaren mugak eta eskasak:}

Garrantzi handikoa izanik ere, idazlan horrek mugak eta eskasak baditu, ondotik ikusiko dugun bezala.

4.1. Garat-en kontradizioak :

Kontradizioak ba dira testu guzian, iragana den urrezko aro "zoriontsu" baten lekukoak bezala nahi baititu aurkeztu Euskaldunak :

\footnotetext{
${ }^{8}$ De la Littérature, Germaine de Staël, 1800.

${ }^{9}$ Ruines ou Méditations sur les révolutions des Empires, Volney, 1791.

${ }^{10}$ Atala, 1801 ; Le Génie du Christianisme, 1802 ; Chateaubriand.
} 
« En observant le Basque dans ce petit nombre même de rapports que peut lui donner un état de société très simple, on peut voir comment les Anciens s'y prenaient pour établir la vertu et le bonheur de l'homme social sur les sentiments et les besoins les plus naturels à l'homme ; il conserve encore, dans son caractère et dans sa vie les traits frappants de cette bonté, de cette grandeur, de cette félicité originelle que nous regardons comme un roman de philosophie ou comme une contradiction qui s'est embellie, en s'enfonçant dans les regrets des premiers âges. »

Beraz, iraganari lotua den bizi molde xume eta tradizionala izan behar dute Euskaldunek ezin bestean. Modernitatetik kanpo geratzen dira nahi ala ez. Garat bide hortarik doa gehitzen duelarik “... peuple étranger à tous les Arts et toutes les Sciences...». Ondoko mendean loratuz joanen den mitologia berri batean sar arazten ditu bere jendakiak eta herrikideak. Eta orduan, « izpiritu soil eta inuxent » horien artean agertu diren artistak eta idazleak -Quintilien eta Garat bera barne- zer bilakatzen dira ? Badirudi euskaldungoa, arte eta jakitate kultoen gostua kontra jarriak direla... alta berak dio bere buruarentzat Euskaldun gisa mintzo dela eta hori goi maileko aldizkari batean.

Gainera, bilakaera gabeko egoera etengabe horrek beste ondorio bat erakartzen du: Euskaldun eta "urrezko aroaren" lekuko egotekotan, Euskaldunek behar dute beti hein berean egon, aldatu gabe, gisa bateko gizarte eta zibilizazio antolaketa ezin hobea moldatu baitute. Beraz, hori aintzinatuz, « Argiek » hain gora ezartzen zituzten balore pedagogikoak, hezkuntza eta ikaskuntza batez ere, funtsik gabekoak ager daitezke Euskaldunen kasuan, beste lehengo jendaldeentzat (salbaientzat) bezala : ez dute zer ikas, ez baitute zer alda. Ondorioz, haien modernitatearen pentsatzeko bidea berak trabatzen dio bere buruari eta, iragana eta tradizioaren sailetara igortzen ditu ezin bestez.

\subsection{Eredu berriaren mugak :}

Gorago erakutsi dugun bezala ez da dudarik «eredu berri » bat aurkeztu duela Euskaldunen aipatzeko. Bainan, Euskal Herria ezagutzen duen nor nahik ikus zezakeen egoera konplexuagoa zela. Xehetasunetan sartu gabe, erran dezagun bakarrik beste Euskaldun eredu batzu ikusgarri zirela adituarentzat.

Hala nola :

- Euskaldun ikasiarena, Etxeberri Sarakoak eta Larramendik molde ezin hobean irudikatzen zutena, gramatika eta hiztegien bitartez euskara, latina eta erdara parekatzen eta uztartzen baitzituzten, euskal gazteriari kultura klasikoaren bidea ideki nahiz.

- Axular, Kardaberaz eta Daguerre bezalako idazle eta eraikitzaileek aurkeztu zuten Euskaldun katolikoa ere hor zuen eta hurbiletik ezagutzen zuen, lehen ikasketak Larresoroko Seminario eraiki berrian egin baitzituen. Begien bistako eredu horri buruz ere ez du hitzik erraten.

Eta osa genezake ereduen zerrenda hori, Sanadon eta Polverel-ek orduko Euskal instituzioentzat, lehengo gizarte antolaketaren gainean oinarrituz, eskubidearen bidetik finkatzen ari ziren eredu hura ere esku menean zuen. Bizkitartean, bere idazlanean, ez du eskubidean oinarritzen den eredu hori kontutan hartzen, ongi ezagutzen duelarik. Tesia horien jakinean da, Lapurdiko Biltzarraren aholkularia baita eta haren ordezkari izanen baita zenbait urte berantago Pariseko gobernuarekilako harremanen kudeatzeko eta Laputarren interesen zaintzeko. Bainan, Mercure-reko gutunean, ez ditu argudio horiek batere baliatzen.

Bukatzeko, aipa dezagun, haurtzarotik aintzina ezagutu duen herri kultura ( kantu, bertsu, tobera-mustra eta beste sorkuntza lanak eta ikusgarriak); herri eredu hortan beste kulturen eragina ageri da adituarentzat eta argi da Euskal bizi moldea ez dela inguruko kulturetarik hain ezberdina. Ageri da ere Euskaldunak ez direla, mendez mende, lehen bezala egon, hots ez direla "Lehengo gizarteen" lekuko garbi edo ez nahasiak" bezala hartzen ahal. 


\section{Bururapena :}

Lettre sur Bayonne et sur les Basques deitu idazlana "Argien mirailan" egina dela ez da dudarik. Ikusi ditugun arrazoin askorengatik erran daiteke, idazlan ideologiko bat -zentzu hoberenean-, ideia berrien arabera moldatzen baitu Euskaldunen aurkezpena Garatek. "Argien eragin zuzena"dakarren idazlana dela gehi dezakegu eta, alde hortarik, pentsa daiteke adibide hoberenetarik bat dela (non ez den lekukotasun bakarra ?).

Bainan ez da ahantzi behar, kontestu berezi batean egina dela. Garai hartako goi mailako astekari kultural batean argitaratua da eta saio literario bezala pentsatua da ere. Berdin, baldintza hortarik heldu zaio zehaztasun zientifiko eskasa, "objektibitate" falta. Zeren eta, begien bistakoa da "mitologizatze" edo eraiketa mitologiko une berri batean sar arazten dituela Euskal gaiak, "Argien" garaiko antropologia eta filosofiaren ildotik abiatuz. XIXgarren mendean jarraikitzaileak eta ondorioak izan ditu "eredu" berri horrek, Baionako liburutegian aurki daitekeen eskuz egina den kopia eragin horren frogatzat hartzen ahal dugularik. Hein batean, Xaho bezalako autore bat bide hortarik abiatzen da zenbait urte berantago ; haren idazlanek "eragin" horren ezaugarriak erakartzen dituzte, bainan, gai hori lantzekoa da oraindik. Agian, Xaho-ri buruz bidean diren ikerketa batzuek xehetasun eta argitasunak emanen dituzte ondoko hilabeetan.

\section{Bibliografia :}

- La Nouvelle Héloïse (1761), Les Confessions (1782), Jean-Jacques Rousseau.

- La vie de mon père (1779), Nicolas Restif de La Bretonne.

- Tableau de Paris (1781), Louis-Sébastien Mercier.

- Supplément au voyage de Bougainville, Denis Diderot

Roger Chartier :

Les origines culturelles de la Révolution française, 1990, Ed du Seuil.

Robert Darnton (Frantses itzulpenentzat) :

L'aventure de l'Encyclopédie, 1982, Ed. Perrin.

Bohème littéraire et révolution, 1983, Ed. Gallimard.

Gens de Lettres, Gens du Livre, 1992, Ed. Odile Jacob.

Michel Duhart :

Dominique-Joseph Garat (1749-1823),

Bulletin de la Société des Sciences, Lettres et Arts de Bayonne, 1992-1993.

Alexander Minski :

Le préromantisme, 1998, Ed. Armand Colin.

Daniel Roche :

Le Siècle des Lumières en Province, 1978. Ed. E.H.E.S.S.-CNRS.

J.I. Tellechea Idigoras :

"Larramendi en las Mémoires de Trévoux », in Symbolae Ludovico Mitxelena septuagenario oblatae, 1985, Vitoria. 


\title{
Eranskina
}

\section{LETTRE SUR BAYONNE ET SUR LES BASQUES}

\author{
DOMINIQUE-JOSEPH GARAT
}

\section{ETABLISSEMENT DU TEXTE POUR LA PRESENTE EDITION}

\section{Remarques générales :}

Cette transcription de l'article paru dans le «Mercure de France» reproduit le texte quasiment à l'identique. Son déchiffrement ne présente pas de difficulté particulière ; cependant, pour en faciliter la lecture, il convient de signaler les points suivants propres à la graphie de la langue française du XVIIIe siècle :

- \& : et.

- $\quad$ oi : ai. Ex : prenois = prenais.

- $\quad$-ans : ants. Ex : enfans = enfants.

L'usage des majuscules à l'intérieur de la phrase ainsi que celui de la ponctuation bien que différents du nôtre- sont maintenus.

\section{Etablissement du texte et publications antérieures :}

Ce texte n'avait pas été republié dans son intégralité depuis sa première parution en 1783. Il a fait l'objet de deux publications partielles :

- 1992: M. Goyhenetche en publie les deux premiers tiers dans les annexes de l'article qu'il consacre à Dominique Garat, l'aîné : Des Frères Garat à Dominique Garat. Cuadernos de seccion -Historia/Geografia - Eusko Ikaskuntza, 1992.

Il transcrit un manuscrit qui se trouve à la Bibliothèque municipale de Bayonne (MRS 94/2-) et qui porte le titre suivant : Discours de Dominique Garat à L'Académie de Bordeaux. Or, ce manuscrit daté de 1784 (Bordeaux -1784) et signé "Garat membre du Parlement» ne correspond qu'à une version partielle de l'article de Dominique-Joseph Garat (Lettre sur Bayonne et sur les Basques) paru dans le Mercure de France le samedi 8 février 1783.

Les éléments de paratexte (Date, lieu, nom et titre de l'auteur) qui figurent sur le document pourraient laisser croire qu'il s'agit du manuscrit utilisé par Dominique Garat lui-même. Cependant, si -comme cela a été supposé- la lettre parue dans le Mercure (en 1783) n'est que le compte rendu de la séance de l'Académie et la reprise du discours de Dominique Garat par son frère cadet ... la datation devient aberrante. D'autres éléments -notamment l'affirmation selon laquelle le rédacteur... n'a pas assisté personnellement à la séance !- compromettent l'attribution du texte original à l'aîné des Garat. Plus sûrement, il s'agit d'une copie de l'article qui a été tronqué par le transcripteur et attribué -par erreur ?- au plus âgé des deux célèbres frères. 
Le copiste a recopié la lettre mot pour mot (avec quelques menues fautes de transcription) jusqu'à la fin du passage consacré aux Basques ( . . ce qu'il en restera ne servira plus qu'à faire voir quelle race d'hommes on a perdue.). Le texte du manuscrit s'achève juste avant l'évocation des deux derniers discours qui ont clôturé la séance de l'Académie, l'un consacré à Quintilien, l'autre à Aliénor d'Aquitaine.

- 1992-1993 : Michel Duhart cite de longs extraits du texte du Mercure de France dans la biographie fournie et très documentée qu'il consacre à Dominique-Joseph Garat et qu'il fait paraître en deux parties dans le Bulletin des Sciences, Lettres et Arts de Bayonne.

\title{
MERCURE DE FRANCE
}

\author{
Samedi 8 février 1783
}

\section{LETTRE SUR BAYONNE ET SUR LES BASQUES}

Un homme de Lettres, Monsieur, qui le jour de la S. Louis, s'est trouvé présent à l'Académie de bordeaux, vous a rendu un compte très intéressant de cette Séance. Cet article m'appartenoit peut-être ; mais l'intérêt même que j'y prenois est une raison de me féliciter de ce que M. de Gudin s'en soit emparé. Le zèle supplée toujours mal au talent, \& il ne suffit pas de s'intéresser fortement aux choses pour en reproduire tout l'intérêt; d'ailleurs, \& n'aurois pu vous dire que ce qu'on m'auroit raconté. M. de Gudin a parlé de ce qu'il a vu \& de ce qu'il a entendu, \& quand on écrit, c'est toujours un grand avantage d'avoir à rendre compte d'une impression qu'on a reçue. Mon regret se borne donc à n'avoir point assisté à cette Séance.

Je regrette de n'avoir point vu une Séance dans laquelle un Représentant de l'autorité souveraine, qui a institué à ses frais un Prix d'émulation pour les jeunes Elèves d'un Savant patriote, a eu le bonheur bien doux de poser lui-même sur la tête de son fils la première couronne du Prix dont il est l'Instituteur. Il semble que la Nature ait voulu le récompenser de ce qu'il a fait pour la Société.

Je regrette de n'avoir pas entendu ce Mémoire où M. Dupré de Saint-Maur a cherché des moyens de rendre à la Ville de Bayonne \& au Pays de Labour le commerce, la population $\&$ le bonheur qu'ils ont perdus. Il suffit d'être homme, il suffit du moins d'être François ${ }^{11}$ pour s'intéresser aux recherches d'un Homme d'Etat sur le sort d'une partie considérable de la France ; mais vous jugez, Monsieur, combien cet intérêt doit être plus vif et plus profond pour un homme qui a reçu le jour dans les lieux dont les besoins \& les malheurs ont été l'objet de ce Mémoire. M. Dupré de Saint-Maur étoit sûr d'attirer l'attention de tous les hommes, mais il ne pouvoit être écouté qu'avec attendrissement par ceux à qui il parloit du bonheur de leur patrie, de leur famille, du sort de leurs pères, de leurs enfans ${ }^{12}$ et de leurs frères. Un Bayonnais ou un Basque ne pouvait fixer sur lui dans ce moment que des yeux mouillés de larmes.

\footnotetext{
${ }^{11}$ François : français.

${ }^{12}$ Enfans : enfants.
} 
Il m'a été refusé de jouir d'un si doux spectacle. Permettez-moi, Monsieur, de chercher à m'en consoler en entretenant un moment le Public, dans votre Journal, des pays \& des hommes dont la destinée a occupé les recherches de M. Dupré de Saint-Maur. Il seroit plus utile à mes compatriotes, il me serait infiniment plus agréable à moi-même de vous envoyer le Mémoire de M. l'Intendant de la Guienne ${ }^{13}$. C'est sous le point de vue où l'on envisage un Administrateur, que ces objets prennent sur-tout pour le Public de l'intérêt \& de l'importance; mais je puis faire connoître le caractère et les talens des hommes dont $\mathrm{M}$. Dupré de Saint-Maur a fait connoître les besoins ; je puis faire voir combien ils sont dignes du bonheur qu'il voudrait leur procurer, et combien le Gouvernement trouveroit d'avantages pour la France entière à aller à leur secours dans la détresse où ils se trouvent. Je ne chercherai point à me défendre de l'amour que toute âme sensible a naturellement pour sa patrie, ce sentiment est peut-être l'éloge le moins suspect d'un pays, \& il est trop vrai, trop profond dans mon cœur pour que je songe à l'exagérer.

Vous devez vous rappeler, Monsieur, que le Mémoire de M. Dupré de Saint-Maur roule Sur les causes de la diminution du commerce de la Ville de Bayonne \& de la dépopulation du pays, \& sur les moyens d'y remédier. Je ne connois pas d'objet plus important pour un Intendant de la Généralité de Guienne.

Ce n'est pas le sort de la Ville de Bayonne seulement que l'état de son commerce intéresse ; une partie considérable de la France, l'Armagnac, le Bigorre, le Béarn, la BasseNavarre fleurissent ou dépérissent à mesure que le commerce de Bayonne dépérit ou fleurit lui-même. Deux rivières qui traversent plusieurs de ces cantons, \& qui coulent assez près de tous les autres, l'Adour et la Nive, viennent se réunir au milieu de Bayonne pour se jeter dans l'Océan, qui en est à une très petite distance, à un quart de lieue. Bordeaux est un point de communication trop éloigné des ces Provinces pour pouvoir y répandre le mouvement \& la vie de son commerce; elles lutteront toujours avec trop de désavantages contre les pays qui se trouvent sur les bords ou auprès de la Garonne, \& dans le commerce il est impossible de soutenir long-temps des concurrences trop inégales. La ville seule de Bayonne est placée de manière qu'elle peut à la-fois \& rassembler leurs richesses dans son sein, \& leur ouvrir le commerce de l'Océan, le seul que puisse donner aujourd'hui aux Peuples les prospérités \& la fortune. L'intérêt général du Royaume est attaché aussi au sort de Bayonne \& des pays qui l'environnent. Placés à une des extrémités de la partie méridionale de la France, ils seront toujours la force ou la faiblesse de l'une des barrières de l'Etat. Si la culture et le commerce y fleurissent, ils répandront leur activité sur l'Espagne qu'ils touchent, et rendront ensuite à la France, par le commerce, une partie des richesses qu'ils auront fait naître en Espagne. Si au contraire on les laisse dans la langueur où ils tombent, ils ne formeront plus bientôt qu'un désert, dont la stérilité se répandra au loin sur les deux Royaumes. Le système des Gouvernements despotiques est de s'entourer, comme le dit Montesquieu, de déserts et de frontières ravagées ; celui des monarchies, au contraire, est de placer une grande partie de leurs forces, de leurs industries et de leur bonheur dans les frontières. Les Etats sont comme les plantes, qui tirent une partie de leurs substances et de leur vie des extrémités de leurs rameaux et de leurs feuilles. Un seul fait peut nous faire voir combien il importe d'aller promptement au secours de ces Provinces $\&$ de cette ville.

Vers la fin de la dernière guerre en $1762 \& 1769$, on évaluoit la population de Bayonne à vingt cinq ou trente mille âmes; on n'en compte pas dix mille aujourd'hui. La dépopulation a été de même à peu près dans tous les cantons dont nous venons de parler. Le Gouvernement qui seul possède les moyens de rendre à ces vastes Pays \& leur Bonheur \& leurs Peuples, doit être parfaitement secondé par l'activité naturelle, le caractère \& le génie de leurs habitants. Nous ne voulons point ici renouveler ces prétentions de Provinces qui,

\footnotetext{
${ }^{13}$ Guienne : Guyenne.
} 
chacune en talent \& en valeur s'attribue la prééminence sur toutes les autres. Les Anciens faisoient l'éloge d'une Ville \& d'une Province, comme on fait aujourd'hui celui d'un Héros, d'un grand Ecrivain, d'un grand Ministre ; mais nous n'avons pas la patience des Anciens pour écouter l'éloge \& nous n'aimons pas plus la vanité d'une Province que celle d'un homme. La vanité s'ennoblit cependant en s'agrandissant dans ses objets; et lorsqu'elle se transforme en amour de la patrie, elle est la source des plus belles actions, comme elle est le sentiment le plus sublime. Cette vanité dont il est permis de s'honorer caractérise singulièrement les Bayonnois. Il n'est rien de bon $\&$ de grand dont ils ne se croyent un peu plus capables que le reste des hommes. Ils conviennent que les circonstances, que la fortune leur a souvent manqué. Mais ils ajoutent qu'ils n'ont jamais manqué à la fortune et qu'ils sont arrivés à la gloire toutes les fois qu'on ne leur a pas fermé tous les chemins. A quoi tiennent les talens et les destinées ? Si l'embouchure de l'Adour eût été un peu plus profonde \& un peu plus large, si en tous temps elle eût pu recevoir des vaisseaux de Roi sans danger, nés à lafois pour la guerre et pour la mer, les Bayonnois auraient sans doute placé souvent leurs noms parmi les Héros de la Marine Royale. Un banc de sable peut-être les a empêchés de donner le jour à des Dugué-Trouin \& à des Tourville ; mais s'ils n'ont pu signaler leurs talens \& leur courage sur ces vaisseaux qui, par leur étendue $\&$ par leur destination, sont les vrais théâtres de la gloire de l'homme de mer, dans une carrière moins brillante $\&$ moins étendue, ils ont eu long-temps une célébrité qui n'étoit guères ${ }^{14}$ moins éclatante. Dans les dernières guerres, les expéditions de leurs corsaires ont fait souvent l'admiration et l'entretien de la France. La patrie elle-même, par les mains du Monarque, leur a décerné souvent des témoignages glorieux de son estime et de sa reconnoissance; et si l'Histoire fait honorer les talens et la valeur si longtemps asservie aux Grands, elle se consacre enfin aux grands noms, elle n'oubliera point ceux des Pelletier, des Lafargue et des Mainrielle (sic). Dans cette guerre on n'a presque pas entendu parler de Bayonne, et c'est sans doute ce qu'il y a eu de plus cruel pour elle dans sa décadence. En redemandant son commerce et ses habitans, c'est surtout la gloire et le bonheur de servir la patrie qu'elle redemande. Les regrets sont devenus amers, ses plaintes se sont fait entendre au moment surtout où elle s'est vue dans le repos \& l'obscurité, tandis que toutes les Villes de mer cherchoient les périls et la gloire dans les deux mondes. J'ai vu des Bayonnois \& ceci n'est point un fait que j'exagère, j'en ai vu qui n'ont rien perdu de leur propre fortune, \& qui pleuraient en songeant que le nom de Bayonne n'avait point été prononcé dans cette guerre. Les talens qui distinguent l'homme de mer ne sont pas les seuls que les Bayonnais croient avoir reçu ce la nature; ils se croyaient aussi propres aux arts \& aux talens aimables qu'à ceux du commerce \& de la marine. Il est possible qu'ils se trompent; mais comment arrive-t-il donc qu'ils donnent toujours d'eux aux étrangers qui visitent leur ville, l'opinion qu'ils en ont eux-mêmes ? Communément, on n'est pas si prompt à entrer dans les sentiments d'un amour propre qui n'est pas le nôtre. Les Etrangers, en effet, paraissent toujours étonnés de trouver à l'extrémité du Royaume, $\&$ au pied des Pyrénées occidentales une ville où la société offre le ton, l'esprit \& l'élégance des mœurs qu'on ne trouve que dans la capitale. Quelqu'un qui entreroit pour la première fois en France du côté de L'Espagne, d'Irun ou d'Urdach, prendrait dans cette première Ville de France une idée à-peu près complète de ce qu'il y a de plus ingénieux et de plus aimable dans les grâces et dans la politesse française. Ordinairement les Etrangers ne se jugent pas si-tôt en France, lorsqu'ils sont encore éloignés de Paris. On voit par combien de motif le sort de la ville de Bayonne a dû intéresser M. Dupré de Saint-Maur, \& combien toute la France doit désirer de connaître les moyens qu'il propose pour relever un commerce qui fait naître tant de richesses et de talens pour le Royaume.

\footnotetext{
${ }^{14}$ Guères : guère.
} 
La destinée du pays de Labour, qui dépend en partie de celle de Bayonne, méritoit cependant une attention particulière, \& M. Dupré de Saint-Maur la lui a donnée. Dans ce pays, l'un des trois cantons qui forment la Biscaye Française, vit un Peuple qui, attaché à la France par l'amour que des sujets doivent à leur Souverain, diffère d'ailleurs absolument des Français par son origine, sa langue, ses coutumes, ses mœurs \& son caractère ; c'est ce Peuple qu'on nomme Basque, mais dont on ne connaît en France que le nom, qui n'est pas même beaucoup connu. Caché entre les gorges des Pyrénées, où les Goths, les Francs et les Sarrasins ont toujours inutilement attaqué sa liberté, il a échappé aux observations des Philosophes, comme aux glaives \& aux chaînes des Conquérans. Rome, dans le temps même où, pour flatter Auguste, elle faisait sans cesse le compte des Peuples qu'elle avait soumis, Rome, qui parle souvent des Basques, n'ose les mettre dans la foule des Nations qu'elle dénombrait dans ses chaînes. Autour d'eux les Peuples ont changé vingt fois de langues, de mœurs et de loix ${ }^{15}$. Ils montrent encore le caractère, ils obéissent encore aux loix, ils parlent encore la langue qu'ils avaient il y a trois mille ans. Chez eux tout a résisté aux siècles, \& l'on dirait que derrière leurs montagnes ils ont trouvé un asyle ${ }^{16}$ contre le temps, ainsi que contre les conquérans \& les oppresseurs. Notre inquiète curiosité va chercher aux deux Pôles des peuplades de Sauvages pour y observer l'homme dans la simplicité des besoins \& des mœurs de la Nature, \& nous ne daignons pas jeter un regard sur un Peuple qui est à côté de nous, presque sous nos yeux, \& qui nous offre l'homme tel qu'il étoit sous l'influence des institutions primitives, où l'instinct de la Nature étoit l'unique législateur des Sociétés. Ici, cependant, au lieu d'un objet de curiosité \& d'instruction, nous en trouvons deux, la Nature \& l'Antiquité ; en observant le Basque dans ce petit nombre même de rapports que peut lui donner un état de société simple, on peut coir comment les Anciens s'y prenaient pour établir la vertu $\&$ le bonheur de l'homme social sur les sentimens ${ }^{17} \&$ les besoins les plus naturels à l'homme. Il conserve encore dans son caractère $\&$ dans sa vie des traits frappants de cette bonté, de cette grandeur, de cette félicité originelle que nous regardons comme un roman de philosophie, ou comme une tradition qui s'est embellie en s'enfonçant dans les regrets des premiers âges. On ne lui taille point, comme dit Montaigne, des devoirs qui passent sa mesure. S'il est bon père, bon fils, frère généreux, mari facile \& tendre, il a rempli tous ses devoirs de citoyen, \& les vertus qui ailleurs sont des sacrifices pénibles, ne sont là que des sentimens toujours prêts à devenir des passions. Pour y être bon citoyen il suffit de n'être pas un méchant homme : voilà les vertus qu'il est facile de faire naître, \& sur lesquelles il est permis de compter. Les loix éternelles de la Nature servent de garants aux loix sociales ; mais lorsqu'on en exige davantage, lorsque la société, dans le délire de ses progrès, s'est fait des besoins qu'elle ne peut remplir que par des vertus surnaturelles, on aura un petit nombre d'âmes sublimes, \& une foule de fripons, de scélérats \& d'hypocrites. Le Basque a de la bonté plutôt que des vertus. Je sais bien que ceux qui l'ont offensé dans quelqu'un de ces sentiments même qui le rendent facile et bon, n'en jugent pas de même. Prompt et terrible dans ses vengeances, plus d'une fois il en a donné des exemples qui ont effrayé, et beaucoup de gens dans les pays voisins se le représentent toujours la carabine ou le poignard à la main ; mais les histoires de ce genre sont celles qu'on exagère le plus, parce que c'est la frayeur qui les raconte. Ceux qui ont vécu parmi les Basques, savent que très-souvent ils sont nobles et généreux jusques ${ }^{18}$ dans les ressentiments même où ils sont implacables. Le Basque est bon, mais de cette bonté naturelle qui ne préserve pas des fureurs des passions; il est bon comme la Nature, qui a des tempêtes et des fléaux, mais qui dans sa marche ordinaire offre partout aux regards l'image simple et touchante de l'ordre \& de la bienfaisance. Il s'en faut bien

\footnotetext{
${ }^{15}$ Loix : lois.

${ }^{16}$ Asyle : asile.

${ }^{17}$ Sentimens : sentiments.

${ }^{18}$ Jusques : jusque.
} 
cependant que l'instinct seul le dirige dans ses actions. Chez ce Peuple étranger à tous les Arts et à toutes les Sciences, le sentiment des droits de l'homme est si profond \& si développé, qu'il sait en tirer la connaissance de tous ses devoirs \& de tous ses droits dans la société. Plus d'une fois j'ai causé dans les champs avec des Laboureurs qui, appuyés sur leur charrue, me tenoient à ce sujet des discours qui valaient mieux que tout le livre de Burlamaque ${ }^{19}$. Cela peut surprendre, j'en conviens, \& on ne manquera point de dire que j'exagère si l'on veut juger du Laboureur Basque par le paysan François. Des écrivains, même des Philosophes Français, ont rejeté plus d'une fois sur un fondement semblable ce que l'Histoire nous raconte de la sagesse et de la raison avancées de quelques Peuples de l'Antiquité, qui ne connaissoient encore d'autre Art que celui de l'Agriculture. De toutes les Nations, nous sommes peut-être celle qui a le plus de peine à comprendre combien les plus belles idées naissent naturellement dans l'homme lorsqu'il est libre, \& qu'il n'est point malheureux. Si des Voyageurs, qui savent observer et peindre des Peuples, ne nous avaient pas fait connaître les hommes qu'ils ont vus dans les vallées \& les montagnes de la Suisse, nous n'aurions peut-être jamais cru sérieusement à l'Histoire des premiers siècles de Rome. Quoiqu'il habite aussi un pays de montagnes, le Basque ressemble on ne peut pas moins au Suisse. La raison forte \& les sentimens droits que celui-ci tire du calme de ses passions, l'autre semble les trouver dans l'énergie et la véhémence des siennes : elles sont terribles, mais elles l'emportent avec violence où la Nature veut le conduire. Les Basquèses ${ }^{20}$ ressemblent bien moins encore aux femmes de la Suisse. Celles-ci, dit-on, sont généralement belles et naïves. Les Basquèses ne sont pas belles en général, assez rarement même elles sont très jolies. Leur sensibilité très vive est aussi trop tôt éclairée pour leur permettre d'être longtemps naïves, et l'on chercheroit inutilement l'innocence des mœurs dans un pays où les mœurs sont très sévères; mais chez aucun Peuple peut-être, les femmes n'ont mis davantage dans tous leurs mouvements et dans tous leurs regards l'expression \& la grâce des passions qu'elles enchaînent, ou du moins qu'elles cachent dans leur cœur. Dans les travaux même des champs, dont elles veulent partager les plus difficiles avec l'homme, elles ont le don de s'embellir \& de plaire par les mouvemens qui les fatiguent. Les formes de leur taille ne sont peut-être pas très remarquables par l'élégance, mais beaucoup par je ne sais quel charme qu'elles prennent par je ne sais quel charme qu'elles prennent dans leur agilité \& dans leur souplesse ; en les voyant marcher, souvent chargées de fardeaux, on devine qu'elles doivent danser avec beaucoup de grâce \& de légèreté ; et de tous les dons qu'elles ont reçu (sic) de la Nature, celui-là du moins a été connu, il leur a fait une espèce de réputation. Leur manière de s'habiller est probablement la même depuis beaucoup de siècles ; mais elles semblent n'avoir renoncé à la variété des modes qu'après avoir trouvé celle qui leur sied le mieux, et qui peut le plus ajouter à leurs agrémens. Leur costume, qui n'appartient qu'à elles, plein de pudeur, mais aussi de goût et d'adresse, embellit aux regards tout ce qu'il leur dérobe. C'est surtout dans leur âme, ouverte à la fois aux plus vifs sentiments de la Nature et aux plus grandes terreurs de la religion, que l'amour a la violence qu'il reçoit de ces combats où la passion et la vertu luttent avec des forces égales, cèdent et triomphent tour à tour. Trop souvent les premières impressions qu'on reçoit d'une femme sont les plus vives et les plus douces, et l'homme n'a pas assez de vertu pour être constant lorsqu'il cesse d'être heureux. Ce désordre, la source de tant d'autres désordres, est peu connu dans les sentimens dont elles font l'objet; tel est le charme inconcevable de leurs passions, qu'elles enflamment \& retiennent par le bonheur qu'elles donnent plus encore que les désirs qu'elles inspirent. Le Basque, naturellement léger \& mobile, qui ne perd point ses affections, mais qui en prend de nouvelles, n'est pas un très fidèle amant, mais il est un mari très fidèle. Ce qu'on a dit des filles de quelques autres pays, on peut le dire de lui. Il se fixe dans le mariage, qui donne, dit-on, tant d'envie de changer.

\footnotetext{
${ }^{19}$ Burlamaque : Burlamaqui

${ }^{20}$ Basquèses : basquaises.
} 
Au reste, je suis persuadé que tout ce qu'il y a de raison \& d'étendue dans les idées de ce Peuple, d'énergique, de fin $\&$ de délicat dans ses sentimens, il le doit beaucoup à la langue qu'il parle. Les belles langues sont comme des instrumens très faciles et très harmonieux, qui perfectionnent le talent qui s'en sert, qui inspirent réellement les idées qu'ils expriment. Cela ne peut paraître un paradoxe qu'à ceux qui n'ont ni oreille ni imagination. Contemporaine des langues que parlaient les Grecs et les Romains, et même probablement d'une origine plus ancienne encore, la langue basquèse, qui ne peut pas avoir toutes les richesses de ces langues, en a tous les grands caractères \& toutes les grandes beautés. Dans les mots simples des sons qui peignent les objets \& les sentiments, dans les mots composés des éléments que l'on reconnoît toujours rassemblés suivant l'analogie la plus exacte $\&$ la plus heureuse des idées, dans la construction une hardiesse incroyable pour entrer dans la pensée de tous les côtés, \& cependant dans les mots des marques sûres \& infaillibles pour fixer rapidement leurs rapports au milieu même des mouvements les plus passionnés \& les plus convulsifs de l'invention. Elle est bornée, il est vrai, dans les objets que peut connaître un Peuple qui n'est qu'Agriculteur; mais quelle féconde richesse d'idées \& de sentiments elle a pu faire naître dans le petit nombre d'objets où elle se renferme! Comme ces enclos où d'habiles Cultivateurs se plaisent à rassembler sur un sol doué de la Nature, les fruits les plus délicats, les fleurs les plus suaves et les plus brillantes; elle réunit dans un espace borné les idées les plus heureuses et les affections les plus touchantes. Avec quelle justesse \& quelle finesse de tact elle a souvent séparé des nuances que les autres Peuples confondent dans les mêmes sensations \& dans les mêmes mots ! Avec quelle grâce \& quels doux accens, seule entre tous les Idiomes, elle a rendu des sentiments qui ailleurs semblent perdus pour le cœur humain, parce qu'ils le sont pour les langues! Lorsqu'après avoir resté quelque temps sans m'en servir j'en reprenois l'habitude, j'avois peine à comprendre l'effet qu'elle produisoit sur moi. En la parlant mes idées devenoient plus faciles, plus pittoresques et plus rapides, toutes mes affections plus fortes, plus douces, plus tendres et plus pénétrantes; je me sentois un autre esprit et une autre âme. Combien de fois alors, en me rappelant la vaine ambition qui me fait former sans cesse des projets \& des plans d'Ouvrages, j'ai regretté avec amertume de ne pouvoir pas les exécuter dans cette langue, qui est comme un génie qui vous inspire! Sans doute je prenois pour mon talen celui du Peuple qui l'a formée ; mais telle était l'illusion où elle me plongeoit, que je me serois cru né pour la gloire, si pour l'obtenir il eût suffi d'écrire dans la langue que j'ai parlée en naissant. Son origine touche à celle des Peuples qui commencent l'Histoire, elle est la même, \& cela m'a souvent donné une idée qui ne peut être bien jugée que par ceux qui connaissent quelqu'une des langues primitives. Les mêmes caractères et presque les mêmes beautés se retrouvent dans toutes celles qui, par leur antiquité, se rapprochent des temps où le genre humain, échappé à quelque grande catastrophe, se remettoit de sa frayeur, sortoit des forêts, descendoit des montagnes, et recommençoit, pour ainsi dire, à rebâtir les sociétés. Ces belles langues, ces langues qui étonnent l'homme comme si elles étaient faites pour être parlées par des êtres plus parfaits que lui, ne seraient-elles pas échappées aussi de ces temps antérieurs à l'Histoire, où l'espèce humaine pouvait avoir, dans ces facultés physiques et morales, une perfection que les malheurs qui ont frappé le Globe lui ont fait perdre dans les ruines du monde primitif ? Voyez les langues dont la naissance est postérieure, aucune ne peut leur être comparée ; \& ce qu'il y a de remarquable, comme toutes les autres avaient à peu près les mêmes caractères \& les mêmes beautés, celles-ci ont aussi toutes à peu près les mêmes défauts \& les mêmes caractères ; elles semblent faites par une espèce \& une espèce inférieure.

Tout ce que j'ai dit jusqu'à présent des Basques, en fait un Peuple curieux pour le Savant, intéressant pour le Philosophe \& pour l'Homme de goût, mais pour attirer l'attention les bienfaits du Gouvernement, il faut qu'on y voie encore un Peuple qui peut être utile à la Nation. Les Basques ont pour l'Agriculture cette estime qui étoit naturelle à tous les Peuples 
de l'Antiquité \& que la Philosophie travaille peut-être inutilement à inspirer aux Peuples modernes. Le Laboureur, fier de ce titre qu'on lui donne \& qu'il prend dans toutes les occasions comme un titre d'honneur, s'assiet ${ }^{21}$ à la table du Gentilhomme, \& s'y croit à sa place, \& le Gentilhomme pense comme lui. Il est facile de voir quel parti un Gouvernement éclairé peut tirer d'un Peuple chez lequel cette opinion, qui a fait la grandeur des Nations anciennes, a toute la force que les siècles donnent aux opinions.

Comme Marin, le Basque a encore des talens qui lui ont fait une de ces réputations qui distinguent les Provinces. Elle doit être incontestable, car elle lui a été faite par des Provinces rivales. Sa voix ne s'est point fait entendre parmi des hommes qui ne parlent que françois ; aussi tout ce qu'il a pu mériter de gloire à cet égard est-il presque absolument ignoré. Qui connaît, par exemple, les titres des Basques à la gloire de la découverte du nouveau Monde ? Quelques-uns de nos Historiens ont eu l'équité d'en parler; mais aucun d'eux ne pouvoit prendre assez d'intérêt à ce coin ignoré de la terre pour les développer dans toute leur force ; il étoit difficile même qu'ils les connussent assez bien pour cela. Ce n'est point ici le lieu d'en faire l'examen. Rien de ce qui regarde un pays où j'ai reçu le jour, et j'ai joui d'un bonheur dont je n'ai même vu ailleurs l'image, ne peut m'être indifférent ; mais j'ai examiné ailleurs cette tradition si honorable à ma patrie, et je me flatte non d'ôter à Colomb une gloire qu'il a bien méritée, et dont il a trop peu joui, mais de faire entrer au moins mes compatriotes en partage d'une si belle gloire : eh ! ne suffit-il pas même de connoître le pays qu'ils habitent pour juger des services qu'ils peuvent rendre ? La richesse d'un Etat consiste sans doute dans la variété des hommes comme dans celle des productions. Il est des espèces d'hommes comme dans celle des productions. Il est des espèces d'hommes qui ne viennent que sur les hauts lieux, sur les montagnes; et lorsqu'un Royaume a l'avantage d'avoir dans son sien le terrein ${ }^{22}$ qui les porte, un bon Gouvernement doit tout faire sans doute pour en cultiver et pour en conserver la race. Celle des Basques diminue sensiblement tous les jours pour des causes dont il est impossible d'arrêter promptement l'influence; elle ne dépérit point; l'espèce conserve son caractère dans toute sa force ; mais elle se perd, le pays se dépeuple, et si l'on ne se hâte d'y porter des secours, ce qu'il en restera ne servira plus qu'à faire voir quelle race d'hommes on a perdue.

C'est beaucoup pour les hommes en place de profiter des Lumières qu'on leur présente, d'encourager ceux qui en cherchent. M. Dupré de Saint-Maur en cherche \& en trouve lui-même. L'homme en place fait encore les fonctions de l'Homme de Lettres \& de Philosophe. Cela est beau, \& cela n'est pas très rare dans notre siècle. On n'oubliera pas les exemples qu'on a vus.

Ce jour semblait être destiné au nom \& à la gloire des Basques dans l'Académie de Bordeaux. M. Dupré de Saint-Maur venait d'en parler avec intérêt dans son Mémoire, et M. Dupaty, Président à Mortier, faisant ensuite l'éloge de Quintilien dans son Essai sur la Vie et les Ouvrages de ce philosophe, faisoit l'éloge d'un Basque sans le savoir peut-être. Cet Ecrivain, né à Calagorri, dans la Celtibérie, étoit un Basque en effet; mais c'est encore comme la découverte du nouveau Monde, tout le monde l'ignoroit. Le premier de sa nation peut-être qui ait vécu dans un pays où l'on cultivait les Arts et les Lettres, il alla soutenir dans la Capitale de l'Empire le bon goût qui ne trouvait plus de défenseur parmi les descendants du siècle d'Auguste. Il sut allier dans ses Ouvrages les idées fines, énergiques et profondes du siècle de Sénèque, de Tacite \& des deux Pline, à ce sens heureux, à cette fleur de bon goût dont la Philosophie peut tenir la délicatesse en étendant d'ailleurs \& en fortifiant toutes les grandes qualités de l'esprit. On peut juger aisément combien un Magistrat exercé longtemps aux triomphes de l'Eloquence dans la plus belle carrière qu'elle ait dans les Gouvernements modernes, combien un esprit aussi philosophique que celui de M. Dupaty a dû puiser de

\footnotetext{
${ }^{21}$ S'assied : s'assiet.

${ }^{22}$ Terrein : terrain.
} 
lumières et faire sentir de beautés dans les Institutions de l'Orateur, le plus beau monument que la Philosophie ancienne ait élevé aux principes de l'Eloquence \& du goût antique. Le public a pu juger par les morceaux que M. Gudin a cités des discours de ce Magistrat. M. Dupaty a fait voir que dans cet Ouvrage, bien plus complet que le Traité du Sublime de Longin, que la rhétorique \& la poétique d'Aristote, Quintilien analyse les principes des Arts avec autant de sagacité qu'Aristote, $\&$ en peint les impressions avec autant de sensibilité que Longin. Sa pensée est large, \& son expression éclatante \& pleine de tableaux. C'est dans son ouvrage que l'on peut se faire une juste idée que celle qu'avoient les Anciens de l'art de former les hommes et les talens. Platon veut que l'éducation des enfans commence dans le sein même de leur mère. Quintilien commence les études de l'Orateur au moment qu'il vient de naître. Son berceau est sa première école. Le Maître l'environne dès qu'il peut sentir ; il veille, pour ainsi dire, sur les organes, pour n'y laisser entrer que des sensations de talen \& de génie. Quintilien veut que dans les premiers sons que l'enfant bégaie, il s'exerce déjà aux tons et aux accens qui doivent charmer ou enflammer dans la Tribune, dans le Sénat, à la tête des Armées. L'Eloquence n'est pas un Art qu'il veut enseigner, mais un talent qu'il veut donner, \& dont il sème les germes dans les organes pour qu'ils se développent avec le corps, avec l'esprit et avec l'âme. Il ne croit point que l'Orateur soit différent de l'homme. Que tous nos Rhéteurs sont loin de cette manière d'envisager les talens (sic), le bon goût et l'Eloquence ! Qu'il y a loin de ces belles et grandes vues, à ces cahiers de rhétorique où l'on croit enseigner à être éloquent \& sublime en donnant s'assez mauvaises définitions de la catachrèse et de la litote ! C'est le sort de M. Dupaty d'être toujours singulièrement applaudi dans toutes les Séances de l'Académie de Bordeaux. Savez-vous, disait un orateur grec, pourquoi mes paroles sont toujours applaudies avec transport par les Athéniens? C'est parce qu'elles leur rappellent mes actions qui veillent toujours à leur bonheur.

Je ne rends point compte de la Séance, et je ne dois point parler des Mémoires des autres Académiciens. Mais le morceau qui a été lu par Dom Carrère intéresse encore la Province ; et quoique cette Lettre excède déjà les bornes d'un article du Mercure, permettezmoi encore, Monsieur, quelques réflexions sur ce sujet ; c'est toujours la même lettre, mais ce n'est plus le même sujet. Ce savant Bénédictin a voulu justifier la mémoire d'Eléonore de Guienne, accusée d'avoir eu, dans les courses pieuses des Croisades, une conduite légère et même un peu galante, nous dit-on. Ce n'est pas seulement les Historiens qui l'ont accusée, c'est encore Louis le Jeune, son mari; mais un mari peut se tromper en pareil cas plus aisément encore que les Historiens et Dom Carrère n'a fait qu'user des droits d'un Historien philosophe, qui peut non seulement apprécier les témoignages de quelques Ecrivains, mais appeler même à son tribunal, et casser les arrêts des siècle. C'est dans le nôtre surtout que les Historiens se sont plus souvent servi de ce privilège de leurs fonctions. On a changé très souvent les places données par ceux qui nous ont précédés, on a détruit ou créé des réputations, flétri ou réhabilité des noms célèbres. Nous ne transmettons pas le dépôt de 1'Histoire à nos descendans comme nous l'avons reçu de nos pères. Cet effet nécessaire des progrès de l'esprit philosophique a eu comme tout le reste ses avantages \& ses inconvéniens.

Les avantages sont si sensibles, qu'ils doivent d'abord frapper tout le monde, quoiqu'on s'en soit apperçu (sic) un peu tard. L'Histoire parle au nom des siècles ; mais c'est un petit nombre d'hommes qui l'écrivent ; $\&$ au fond tous ces témoignages si imposans et si magnifiques des Nations des âges, se réduisent souvent à deux ou trois voix qui parlent loin du monde et des hommes. Quand le génie parle sur-tout, on croit entendre tous les siècles, et on ne doute pas plus des faits qu'il peint que de la beauté des tableaux qu'il en trace. Nous lui donnons notre foi avec notre admiration. Telle est la séduction du grand talent. On fait des objections à Suétone; on est aisément Philosophe avec lui ; mais avec Tacite on est crédule, \& les faits embellis de son style semblent être une tradition sacrée contre laquelle le doute n'est point permis. Je sais qu'on a dit le contraire, et que beaucoup de gens prétendent avoir 
plus de confiance dans la simplicité de Suétone. Je rends compte de l'impression que j'ai reçue. Il peut donc être utile, il est même souvent nécessaire de se pourvoir devant les siècles futurs contre ce qu'on appelle les jugements des siècles passés. Il ne faut pas qu'une injustice ou une erreur ait le droit de devenir éternelle, parce qu'elle est devenue historique. Voyez où commence l'Histoire, \& y répandent de la chaleur et du mouvement; des crimes ou de l'innocence de quelque personnage qui occupe une grande place dans l'Histoire, du moment que l'Histoire accuse ou défend devant le tribunal des siècles, \& que le Lecteur qu'il interroge, à qui il demande sa voix \& son suffrage, devient lui-même une partie de cet auguste tribunal. Qui pourrait comparer l'effet du simple récit du meurtre de Clodius, à celui du beau discours de l'Orateur Romain pour Milon? Quand Tacite juge un homme, on ne se croit pas seulement devant le Sénat ou les Comices, on a devant les yeux l'assemblée du genre humain. Voltaire et Hume sont parmi les modernes ceux qui ont le plus contribué à établir cet usage de réviser les procès des coupables puissans que l'Histoire absout, ou des infortunés illustres qu'elle condamne, \& tous les deux ont porté dans des examens ou un respect profond de la vérité, ou un grand amour de l'humanité.

L'Ecrivain dont l'âme ne sera pas remplie par ces deux sentimens ou par l'un d'eux au moins, ne laissera voir que le danger de jeter tant de doutes et d'incertitudes sur des faits adoptés par une espèce de consentement universel. Il portera devant le tribunal des siècles l'esprit de chicane \& de convention qui a dégradé trop souvent celui de la justice. Privé du talent de prendre les faits et les hommes, \& du génie qui fait sortir des vérités nouvelles des faits connus et avoués, il mettra l'audace $\&$ le trouble de la dispute à la place du génie $\&$ du talent. Il n'écrira l'Histoire que pour y chercher des exemples \& des preuves d'une passion chérie, d'une opinion par laquelle on veut trouver quelque parti, \& alors, c'est un faussaire qui entre dans les archives des âges. Tant de doutes \& de problèmes qu'on fait entrer dans l'Histoire en affaiblissant la foi qu'elle demande, affaiblissent aussi l'utilité que l'on retire de l'autorité de ses arrêts ; le méchant ne la craindra plus, le juste ne mettra plus en elle son espérance, elle ne sera plus pour l'homme cette espèce d'immortalité que son âme trouvoit sur la terre ; d'ailleurs, \& ceci me paroît important, souvent au bout de quelques siècles, même de quelques années, les preuves sur lesquelles l'Histoire s'est décidée, sont détruites ou affaiblies, les véritables pièces du procès ne se retrouvent plus ; \& quoique l'arrêt ait été très juste lorsqu'on l'a prononcé, il peut prendre dans la suite les apparences de l'injustice. La logique pour ces sortes de discussions, exige d'un genre d'esprit qui se trouve plus rarement encore que le talent de l'Historien, et cela en prouve le danger.

On peut remarquer que c'est sur la réputation des femmes célèbres qu'on a élevé le plus de doutes et de problèmes. Brunchaut, Frédégonde, Blanche de Castille, Marguerite de Valois, Marie Suard, etc, etc, etc. ont trouvé tout à tour des accusateurs et des défenseurs dans les Ecrivains qui en ont parlé. L'Histoire est devenue une arène, où des champions sont descendus pour se battre pour ou contre leurs vertus. Il semble qu'il soit plus difficile à l'Histoire même de pénétrer dans le caractère des femmes: les secrets et les mystères si naturels à leur sexe, ce besoin qu'elles ont de cacher les sentiments les plus doux à leur cœur, les faiblesses les plus nécessaires à leur bonheur, enveloppe très souvent leur vie publique dans les mystères de leurs passions. Peut-être même que, jusques dans l'Histoire, où il ne reste d'elles que leur souvenir, elles exercent encore quelques chose de l'empire de leurs charmes, de la séduction de leurs faiblesses. Un Historien vulgaire a beau raconter leur vie, il les laisse dans le tombeau; il n'en a rien à craindre ; mais le talent qui les fait revivre, en leur redonnant leurs grâces et leur jeunesse, leurs goûts et leurs passions, environne lui-même son jugement d'illusions et de pièges; et pour l'homme sensible qui veut les juger, je les crois plus dangereuses encore au tribunal de l'Histoire qu'à celui des loix. Il est impossible, par exemple que les charmes de Marie Suard, les agrémens de son esprit, la sensibilité touchante et élevée de son âme ne laissent désirer fortement de croire à son innocence. Quel tableau la 
Philosophie procurera à l'Histoire ! que de larmes le talent fera verser sur son échafaud, si l'on parvient à faire d'une femme si aimable une victime innocente de la jalousie, dont la tête va tomber sous la hache des bourreaux! On voit de combien de passions l'Historien est environné, lorsqu'il touche à ces personnes et à ses événemens, qui sont des foyers de passions. En lisant M. Hume, on fait des vœux pour que Marie Suard soit innocente ; on n'en doute plus lorsqu'on a lû l'excellente Dissertation de M. Gaillard; mais les plus fortes preuves de sa vertu sont peut-être les larmes que l'on donne à ses malheurs.

La destinée d'Eléonore de Guienne n'a été ni aussi tragique ni aussi touchante ; mais elle doit avoir plus d'intérêt encore pour la Province où Dom Carrère écrit. Ce que nous avons pu connoître de sa manière de discuter, le ton honnête et impartial de son style annonce un ami de la vérité. S'il discute, ce n'est point par impuissance de peindre, c'est parce qu'un esprit sage doute souvent, \& qu'il est difficile d'avoir de la sagacité sans voir quelquefois différemment des autres. On voudroit seulement qu'il eût parlé des erreurs et non pas des calomnies des Historiens. Eléonore, dans les courses de la Croisade, étoit très jeune encore ; elle avoit un de ces caractères passionnés \& brillans d'où semblent sortir les événemens de l'Histoire. Son mari, Louis le jeune étoit très dévot, même un peu triste peut-être. Il se plaignait souvent de sa femme, \& l'Histoire l'a pris au mot. Que pouvons-nous en savoir, et que devons nous en croire aujourd'hui ? Il me semble qu'il n'est pas très nécessaire d'avoir une opinion là-dessus. S'il est question de ses galanteries, par exemple, et que Dom Carrère veuille absolument qu'elle ne s'en soit permise aucune, ne serait-ce pas ici le cas de dire àpeu-près comme Mme de Lassai à son mari : Eh! mon Dieu, Monsieur, comment faites-vous pour être si sûr de ces choses-là?

J'ai l'honneur d'être, Monsieur, etc. GARAT. 